\title{
EM TEMPOS DE PANDEMIA DO COVID-19, ENFRENTANDO UM ANTIGO INIMIGO: DENGUE ${ }^{1}$
}

\author{
Jessica Morais da Silva Paim²; Anderson Abadde Moraes ${ }^{3}$; Francine \\ Santellano Susin ${ }^{4}$; Júlia Pauli Saccol ${ }^{5}$; Martha de Souza ${ }^{6}$; Adriana Pereira \\ Dall'Asta ${ }^{7}$
}

\section{RESUMO}

Objetivo: abordar a vivência dos discentes em meio a pandemia demonstrando a importância de abordar sobre outras doenças de impacto na saúde pública. Metodologia: Se trata de um relato de experiência realizado durante a disciplina de Temáticas Emergentes em Enfermagem e Saúde, do Curso de Enfermagem da Universidade Franciscana, disciplina, realizado no período de março a julho de 2020. Resultado e discussão: A Dengue é uma doença reemergente, sendo considerada uma doença dinâmica, dado o fato que o paciente pode apresentar uma rápida evolução para um estado crítico e sendo um importante problema de saúde pública que vem crescendo a sua incidência em Santa Maria. Conclusão: É importante, que a população siga atenta e se conscientize sobre a dengue, percebendo sintomas leves e utilizando as portas de entrada corretas do sistema de saúde para tratar o início da doença e consequentemente não evoluindo para quadros mais graves.

Palavras-chave: Enfermagem, Doença Reemergente, Saúde Pública.

Eixo Temático: Atenção Integral e Promoção à Saúde (AIPS)

\section{INTRODUÇÃO}

A Dengue é uma importante doença que afeta principalmente regiões tropicais e em desenvolvimento, por tanto a América do Sul está localizada em sua área de

\footnotetext{
${ }^{1}$ Relato de experiência vinculado a disciplina de Temáticas Emergentes em Enfermagem e Saúde e ao PET-Saúde Interprofissionalidade da UFN.

${ }^{2}$ Acadêmico do Curso de Enfermagem - UFN. Email: jessicamoraissilva91@gmail.com

${ }^{3}$ Acadêmico do Curso de Enfermagem - UFN. Email: anderson.abbade.moraes@gmail.com

${ }^{4}$ Acadêmico do Curso de Enfermagem - UFN. Email: franssusin@gmail.com

${ }^{5}$ Psicóloga. Email: juliapsaccol@gmail.com

${ }^{6}$ Orientadora - Enfermeira. Email: marthahts@gmail.com

${ }^{7}$ Orientadora - Enfermeira - Doutora, Professora do Curso de Enfermagem - UFN. Email: adrianadallastapereira@gmail.com
} 
atuação. No Brasil, as arboviroses, compostas por Zika vírus, Febre Chikungunya, Febre Amarela e Dengue, constituem um importante problema de saúde pública uma vez que possuem o mesmo vetor de transmisão, o mosquito Aedes aegypti (NETO, et al., 2020).

O mosquito Aedes aegypti é uma espécie sinantrópica e antropofílica, facilmente prolifera-se em áreas urbanas e densamente povoadas, assim em meados da década de 2000, a Dengue foi considerada pela Organização Mundial da Saúde (OMS) uma doença negligenciada, ganhando o status de promotora e perpetuadora da pobreza, devido sua associação epidêmica com os dados de precariedade de saneamento básico e portanto, a Dengue é considerada uma problemática permanente no Brasil desde o início do século XX (CAVALLI, et al., 2019).

Percebe-se que a urbanização, o aumento da densidade populacional, as condições socioeconômicas e de moradia inadequadas, o saneamento básico precário ou inexistente, os hábitos comportamentais das pessoas, o aquecimento global entre outros fatores que podem ser apontados como importantes fatores macrodeterminantes da ocorrência das arboviroses associadas ao A. aegypti, como é o caso da dengue (NETO, et al., 2020).

Por outro lado, observa-se que, O novo coronavírus, denominado SARS-CoV2, que causa a doença COVID-19, foi detectado em 31 de dezembro de 2019 em Wuhan, na China. Em 9 de janeiro de 2020, a Organização Mundial da Saúde (OMS) confirmou a circulação deste vírus. No dia seguinte, a primeira sequência do SARSCoV-2 foi publicada por pesquisadores chineses. Já em 16 de janeiro, foi notificada a primeira importação em território japonês. Em 21 de janeiro, os Estados Unidos reportaram seu primeiro caso importado. No dia 30 de janeiro, a OMS declarou a epidemia uma emergência internacional. Ao final do mês de janeiro, vários países já haviam confirmado importações de caso, incluindo Canadá, Estados Unidos e Austrália. No Brasil, em 7 de fevereiro, havia 9 casos em investigação, mas sem registros de casos confirmados (LANA, et al., 2020).

Em meio ao surgimento deste novo vírus e o decreto de situação de pandemia vivenciado no momento, não se pode esquecer que existe outras doenças que são importantes mantermos atenção, como é o caso da dengue. 


\section{OBJETIVO}

Abordar a vivência dos discentes em meio a essa pandemia tendo a visão da importância de abordar sobre outras doenças de impacto na saúde pública.

\section{METODOLOGIA}

O presente trabalho é de caráter descritivo, do tipo relato de experiência, realizado a partir da vivência dos discentes durante a pandemia do coronavírus em que foi criado um desafio para os discentes sobre o momento em que está sendo vivido. Desenvolvido a partir da disciplina de Temáticas Emergentes em Enfermagem e Saúde, do Curso de Enfermagem da Universidade Franciscana (UFN). Realizado no período de março a junho de 2020. De acordo com Gil (2008), o relato de experiência da margem para o pesquisador relatar suas experiências e vivências junto com o saber científico e assim contribuindo de forma relevante para sua área de atuação.

A seleção do material que embasou este estudo, contemplou publicações contendo artigos, publicações da Secretaria da saúde do Rio grande do Sul, além de sites de notícia confiáveis, adotou-se esta metodologia por ser uma temática muito atual. As bases de dados utilizadas para procurar os artigos foram Biblioteca Virtual em Saúde (BVS), contemplando a Biblioteca eletrônica Scientific Eletronic Library Online (SciELO) e Literatura Latino-Americana e do Caribe em Ciências da Saúde (LILACS).

\section{RESULTADOS E DISCUSSÃO}

Frente a pandemia em curso pelo SARS-COV-2, deve-se observar no contexto atual o impacto dos fenômenos que envolvem a relação do homem com a natureza, sendo uma oportunidade para rever e compreender as necessidades para alcançar 
uma Saúde Única com abordagem na relevância das interações entre o animal, o ambiente e o homem como elementos chave para diversas doenças emergentes (CHAVES; BELLEI, 2020). Através disso, como componentes da área da saúde, somos uma das partes fundamentais para a disseminação de informações coerentes, as quais podem contribuir no dia a dia da população.

Diante do exposto, a professora da disciplina de Temáticas Emergentes em Enfermagem e Saúde do curso de Enfermagem da UFN propôs um desafio, o qual consistia na busca de alternativas para disseminar informações sobre a temática da pandemia em curso, sendo este tema relevante para esta disciplina. O desafio consistia em dividir a turma em grandes grupos e estes por sua vez deveriam desenvolver uma forma de abordar a temática, porém, elaborando novas formas de informar a população, respeitando assim, as medidas de contenção e prevenção ao novo vírus circulante. Optou-se por abordar a temática de maneira online.

A proposta inicial se propunha à formas de disseminar informações que auxiliassem na prevenção e combate ao COVID-19, uma doença emergente. No entanto, após um diálogo com a professora da disciplina, o grupo optou por abordar uma temática reemergente na cidade, a dengue. A temática se mostrava intimamente relacionada com a disciplina, sendo importante para a saúde pública, mas acabou por ser menos priorizada com a urgência da pandemia. Com isso, regiões da cidade de Santa Maria estavam apontando dados de grande incidência de dengue, demonstrando a importância de disseminar maiores informações sobre o tema para a população. Com o conhecimento da problemática, alunos da disciplina da enfermagem junto a bolsistas do PET-Saúde Interprofissionalidade da UFN trabalharam em conjunto na produção de materiais, com objetivo de que fossem compartilhados online, abordando a temática da dengue e respeitando o isolamento social necessário.

A Dengue é uma doença reemergente, que costuma ignorar todas as tentativas de controle e exerce um impacto negativo no contexto econômico, manifestando-se principalmente em regiões de vulnerabilidade social. Esta doença produz epidemias recorrentes em regiões tropicais, principalmente em países em desenvolvimento, como exemplo, a América do Sul, mas também já sendo registrada em espaços extra 
tropicais e em países já considerados desenvolvidos como Estados Unidos, França, Japão, Portugal e Croácia (NASCIMENTO, et al., 2019).

Desde o século $X X$, o Brasil registra casos de Dengue, assim podendo-se afirmar a existência de um ciclo de reincidencia no país. A doença possui carater endêmico-epidêmico, espalhando-se em todos os estados brasileiros. Por seu vetor de transmissão ser um mosquito, se espalha facilmente através dos transportes de alimentos e mercadorias, facilita-se também do clima tropical e das condições de vulnerabilidade social. O mosquito rapidamente dissemina a doença, causando um alto índice de infecção. Há anos registraram-se mais de um milhão de doentes notificados e grande letalidade. Com aproximadamente $5 \%$ dos casos graves, a dengue caracterizou-se como um dos principaiss problemas de saúde pública no Brasil (CAVALLI, et al., 2019).

No Rio Grande do Sul foi identificado o primeiro foco do mosquito Aedes Aegypti em 1995, mas somente no ano de 2007 o estado registrou o primeiro caso de dengue autóctone. O Centro Estadual de Vigilância em Saúde do Rio Grande do Sul (CEVS/RS) divulgou através do informativo epidemiológico das arboviroes que até a semana Epidemiológica 22 (24/05/2020 a 30/05/2020) havia um total de 5.409 casos suspeitos de dengue no estado, destes, 3.160 casos confirmados, 2.784 casos autóctones, 376 casos importados, 100 casos inconclusivos, 1.436 casos descartados e 713 aguardando investigação. Destaca-se que, todos os municípios com casos autóctones são considerados infestados pelo Aedes Aegypti (BRASIL, 2020).

Segunda a Coordenadoria Regional de Saúde, até a semana Epidemiológica 22, o município de Santa Maria resgistrava 413 casos notificados e 73 confirmados. Comparado ao mesmo período do ano anterior, que foram registrados 23 notificações e 7 confirmações, evidencia-se salto significativo no número de casos da doença (BRASIL, 2020). Assim, salienta-se que as medidas de combate, prevenção e educação em saúde são de extrema importância em Santa Maria, uma vez que além da alta incidência de dengue na região, também vivencia-se a pandemia de COVID19, fato este que gera enorme sobrecarga aos serviços de saúde da região.

A Dengue é considerada uma doença dinâmica, dado o fato que o paciente pode apresentar uma rápida evolução para um estado crítico. Portanto, a coleta de 
dados através da anamnese e do exame físico são primordiais para a identificação dos casos e orientação das medidas terapêuticas cabíveis (CAVALLI, et al., 2019). Assim, pode-se afirmar que o reconhecimento precoce dos sinais é de extrema importância para uma melhor resposta e manejo do paciente, diminuindo a incidência de casos graves da doença.

Observa-se ainda que, na realização da anamnese e exame físico com os usuários, existem sinais de alerta da dengue que são essenciais e devem ser observados. A grande parte dos sinais de alerta são resultante do aumento da permeabilidade vascular, a qual marca o início do deterioramento clínico do paciente e as possíveis evoluções para o choque por extravasamento de plasma, que podem dessa forma gerar os casos graves de dengue. Dentre esses sinais, observa-se: Dor abdominal intensa (referida ou à palpação) e contínua; Vômitos persistentes; Hipotensão postural e/ou lipotimia; Letargia e/ou irritabilidade; Acúmulo de líquidos (ascite, derrame pleural, derrame pericárdico); Hepatomegalia maior do que $2 \mathrm{~cm}$ abaixo do rebordo costal; Sangramento de mucosa; Aumento progressivo do hematócrito (BRASIL, 2016).

São considerados casos suspeitos de dengue pacientes que apresentam febre alta e pelo menos mais dois dos seguintes sintomas: cefaleia, mialgia, artralgia e prostração, e devem ser notificados ao centro de Vigilância Epidemiológica da cidade. Casos onde a potencialidade de agravamento é facilmente identificada possuem além dos sintomas clássicos, podemos identificar sinais de alarme, tais como: vômito persistente, dor abdominal, hemorragia, letargia, edema, hipotensão postural, aumento de hematócrito, hepatomegalia e plaquetopenia abrupta, assim necessitando de atendimento especializado. O monitoramento contínuo e a reposição hirica são importantes durante o manejo do paciente, uma vez que os sinais de alarme e o agravamento do quadro costumam ocorrer no período de remissão febril (CAVALLI, et al., 2019).

Percebe-se assim que a melhor forma de prevenção da dengue é evitar a proliferação do mosquito, através da eliminação de água paradas que podem se tornar possíveis criadouros, como por exemplo pneus, vasos de plantas, lagões de água, garrafas plásticas, piscinas sem manutenção e/ou uso e até mesmo em recipientes 
pequenos, como tampas de garrafas. Outro ponto a ser ressaltado é o cuidado na utilização de roupas que minimizem a exposição da pele durante o dia, em locais que já existem casos da doença, podendo assim gerar alguma proteção às picadas e sendo uma medida adotada, principalmente durante surtos. Repelentes e inseticidas também podem ser usados, seguindo as instruções do rótulo. Mosquiteiros concedem boa proteção para aqueles que dormem durante o dia, momento onde o mosquito esta, mas ativo, sendo como exemplo bebês, pessoas acamadas e trabalhadores noturnos (BRASIL, 2020a).

Diante deste contexto, o grupo decidiu realizar infográficos que pudessem passar informações para a população sobre esta doença reemergente, a qual também pode levar a morte em casos mais graves. Os infográficos foram construídos de forma que abordassem os principais pontos da doença e formas de prevenção.

Outro ponto importante de se ressaltado é a relevância da escolha do grupo em abordar a temática. Devido ao contexto da pandemia, as portas de entrada do SUS no município de Santa Maria, de acordo com a prefeitura, estão com prioridades diferentes, específicas de cada serviço. Com essas informações, formulou-se um infográfico explicativo para a população, o qual demonstrava qual serviço deveria ser procurado diante de sintomas de dengue ou de COVID-19.

A produção dos infográficos foi disponibilizada nas redes sociais, e posteriormente, devido ao vínculo com o PET-Saúde, repassado para o médico responsável de uma Estratégia de Saúde da Família (ESF) da região oeste de Santa Maria, local que demonstrava alta incidência de novos casos. O material foi utilizado na ESF durante sua rotina de trabalho, sendo impresso e repassado à população e profissionais do local, apontando a importancia da fala sobre a doença.

\section{CONCLUSÃO}

Conclui-se que a escolha de uma doença que não fosse a pandemia do COVID19 para a realização da atividade foi de grande validade, visto a alta incidência da dengue na cidade de Santa Maria. É fundamental a conscientização da população 
sobre a dengue, seus sintomas, locais de referência e, principalmente, suas formas de prevenção.

Através da conscientização da população sobre a dengue, ao perceber sintomas leves e utilizar as portas de entrada corretas (ESF e UBS), tratando o início da doença e consequentemente não evoluindo para quadros mais graves, evita a necessidade de leitos no SUS, impactando diretamente na situação atual da COVID19, permitindo a disponibilidade de leitos livres que podem ser necessário para pacientes com COVID, assim, não superlotando os serviços e possibilitando seu acesso para casos graves.

O desafio da disciplina e da construção dos materiais se mostrou importante para relacionar o momento vivenciado e perceber que o foco está na pandemia, mas outras doenças também exigem atenção e são relevantes para a saúde pública. Percebeu-se, enquanto futuros profissionais da saúde, a necessidade de ter uma visão ampla do que acontece em nosso contexto e ter a habilidade de abranger todos os pontos que afetam ou podem afetar a população.

\section{REFERÊNCIAS}

BRASIL. Ministério da Saúde. Dengue: diagnóstico e manejo clínico: adulto e criança. Secretaria de Vigilância em Saúde, Departamento de Vigilância das Doenças Transmissíveis. - 5. ed. - Brasília: Ministério da Saúde, 2016.

BRASIL. Centro Estadual de Vigilância em Saúde. Situação

Epidemiológica/dados. 2020. Disponível em: <https://www.cevs.rs.gov.br/situacaoepidemiologica-dados-591326b287597>. Acesso em: 23 jun. 2020.

BRASIL. Ministério da Saúde. Dengue: sintomas, causas, tratamento e prevenção. 2020a. Disponível em: https://www.saude.gov.br/saude-de-a-z/dengue. Acesso em: 01 jul. 2020.

CAVALLI, F. S., et al. Controle do Vetor Aedes Aegypti e Manejo dos Pacientes com Dengue. J. res.: fundam. Care, v. 11, n. 5, p.1333-1339, out./dez. 2019.

CHAVES, T. S. S., BELLEI, N. SARS-COV-2, o novo Coronavírus: uma reflexão sobre a Saúde Única (One Health) e a importância da medicina de viagem na emergência de novos patógenos. Rev Med., São Paulo. v. 99, n. 1, jan.-fev 2020.

GIL, A.C. Como elaborar projetos de pesquisa. 5. ed. São Paulo: Atlas, 2008. 


\section{PUFN}

LANA, R. M., et al. Emergência do novo coronavírus (SARS-CoV-2) e o papel de uma vigilância nacional em saúde oportuna e efetiva. Cad. Saúde Pública v. 36, n., p. 1-5. 2020.

NASCIMENTO, M. C., et al. Significados da dengue para enfermeiros da atenção primária à saúde. Rev Min Enferm, v. 23, p. 1-7, 2019

NETO, F. C., et al. Ocorrência de dengue e sua relação com medidas de controle e níveis de infestação de Aedes aegypti em uma cidade do sudeste brasileiro. BEPA, v. 17, n.195, p. 3-19, 2020. 